\title{
Transmission dynamics of Tasmanian devil facial tumor disease may lead to disease-induced extinction
}

\author{
Hamish McCallum, ${ }^{1,4}$ Menna Jones, ${ }^{1,2}$ Clare Hawkins, ${ }^{1,2}$ Rodrigo Hamede, ${ }^{1}$ Shelly Lachish, ${ }^{3}$ David L. Sinn, ${ }^{1,2}$ \\ Nick Beeton, ${ }^{1}$ and Billie Lazenby ${ }^{2}$ \\ ${ }^{1}$ School of Zoology, University of Tasmania, Private Bag 5, Hobart 7001 Tasmania, Australia \\ ${ }^{2}$ Department of Primary Industries and Water, Hobart 7001 Tasmania, Australia \\ ${ }^{3}$ School of Integrative Biology, The University of Queensland, Brisbane 4072 Australia
}

\begin{abstract}
Most pathogens threatening to cause extinction of a host species are maintained on one or more reservoir hosts, in addition to the species that is threatened by disease. Further, most conventional host-pathogen theory assumes that transmission is related to host density, and therefore a pathogen should become extinct before its sole host. Tasmanian devil facial tumor disease is a recently emerged infectious cancer that has led to massive population declines and grave concerns for the future persistence of this largest surviving marsupial carnivore. Here we report the results of mark-recapture studies at six sites and use these data to estimate epidemiological parameters critical to both accurately assessing the risk of extinction from this disease and effectively managing this disease threat. Three sites were monitored from before or close to the time of disease arrival, and at three others disease was well established when trapping began, in one site for at least 10 years. We found no evidence for sex-specific differences in disease prevalence and little evidence of consistent seasonal variation in the force of infection. At all sites, the disease was maintained at high levels of prevalence ( $>50 \%$ in $2-3$-year-old animals), despite causing major population declines. We also provide the first estimates of the basic reproductive rate $R_{0}$ for this disease. Using a simple age-structured deterministic model, we show that our results are not consistent with transmission being proportional to the density of infected hosts but are consistent with frequency-dependent transmission. This conclusion is further supported by the observation that local disease prevalence in 2-3-year-olds still exceeds $50 \%$ at a site where population density has been reduced by up to $90 \%$ in the past 12 years. These findings lend considerable weight to concerns that this host-specific pathogen will cause the extinction of the Tasmanian devil. Our study highlights the importance of rapidly implementing monitoring programs to determine how transmission depends on host density and emphasizes the need for ongoing management strategies involving a disease-free "insurance population," along with ongoing field monitoring programs to confirm whether local population extinction occurs.
\end{abstract}

Key words: basic reproductive number $R_{0}$; conservation biology; extinction; facial tumor disease; pathogen transmission; Sarcophilus harrisii; Tasmanian devil.

\section{INTRODUCTION}

Population decline caused by infectious disease is increasingly being recognized as a major threat to the survival of some species (McCallum and Dobson 1995, Lafferty and Gerber 2002, de Castro and Bolker 2005, Hoffmann et al. 2008). Recent examples of infectious disease threatening the extinction of endangered species include the Ebola virus affecting western gorillas (Leroy et al. 2004), the fungus Batrachochytrium dendrobatidis in numerous frog species worldwide (Berger et al. 1998, Lips et al. 2006), rabies in Ethiopian wolves (Randall et al. 2006) and African wild dogs (Vial et al. 2006), and avian malaria and birdpox threatening Hawaiian land birds (van Riper et al. 1986, 2002). In all these examples,

Manuscript received 22 September 2008; revised 13 February 2009; accepted 25 March 2009. Corresponding Editor: M. F. Antolin.

${ }^{4}$ E-mail: hamish.mccallum@utas.edu.au the pathogen in question has a broad host range, including one or more reservoir species on which the disease can be maintained at high prevalence, even as the threatened species decline towards extinction.

The Tasmanian devil, Sarcophilus harrisii, the largest surviving marsupial carnivore, has suffered massive population declines as a result of Tasmanian devil facial tumor disease (hereafter DFTD), a recently emerged novel infectious cancer (Hawkins et al. 2006, McCallum et al. 2007, Jones et al. 2008, McCallum 2008). First reported in northeastern Tasmania in 1996, DFTD has spread south and west over the majority of the geographic range of the species, leading to a total population decline of $>60 \%$, with declines in excess of $90 \%$ in the Northeast, where it has been present for the longest time (Hawkins et al. 2006, McCallum et al. 2007). The disease is an infectious cancer, spread as a transmissible cell line (Pearse and Swift 2006). This unusual infection process is thought to be possible 
because of the extremely low genetic diversity of the devil population, particularly in the Major Histocompatibility Complex (MHC), the vertebrate immune system genes closely associated with self-nonself recognition. All individuals examined by Siddle et al. (2007) from the eastern part of the state possessed very similar MHC genotypes, which were described as "functionally identical." The recent emergence of DFTD and its intimate genetic relationship with Tasmanian devils make it highly unlikely that there are alternate hosts, and no evidence of the disease in any other species has been observed (Hawkins et al. 2006, McCallum 2008).

Tasmanian devils bite each other frequently during sexual encounters and interactions over food; adults are most commonly bitten around the head region (Hamede et al. 2008). It is highly likely that biting is the primary means of tumor transmission, given that tumors are almost invariably first observed on the head or face (Loh et al. 2006, Pyecroft et al. 2007). However, transmission through uninfected animals scavenging on the carcasses of other devils that have died from the disease or through infected and susceptible devils feeding on the same prey carcass cannot be entirely discounted.

The incubation period of DFTD is currently unknown. The infection process through transfer of viable cancer cells suggests that transmission is unlikely to occur before visible tumors around the face and mouth are present. This implies that the latent period (the time from acquisition of infection to infectiousness) is at least as long as the incubation period (the time between infection and first appearance of clinical signs). There is one anecdotal record of an individual held in captivity that first developed disease 10 months after its removal from an infected population, and trapping records (Tasmanian Department of Primary Industries and Water [DPIW], unpublished manuscript; M. E. Jones, unpublished data) suggest that tumors develop from small nodules to large friable tumors over a period of $2-$ 3 months. Once a visible tumor is present, the disease is typically fatal within 6 months (Hawkins et al. 2006).

Greatly reduced survival and population growth rates in disease-affected populations indicate that population declines could lead to local extinctions within 15 years of disease arrival (Lachish et al. 2007). In addition, estimates of disease spread indicate that DFTD will cover the entirety of the devils' range in as little as 5 years time (McCallum et al. 2007). Extrapolation of these observed trends has led to concerns that this novel disease may lead to the extinction of Tasmanian devils in the wild in the next 25 to 30 years (McCallum et al. 2007).

According to conventional host-pathogen theory, however, a single-host pathogen should become extinct before its sole host because transmission is usually dependent on host density. Below a threshold density, transmission is reduced sufficiently that the pathogen cannot be maintained within the host population (Anderson 1991). Only if pathogen transmission is independent of host density can a single-host pathogen in itself lead to the extinction of its host (de Castro and Bolker 2005). Hence, to determine the risk of extinction to the Tasmanian devil population from DFTD, we require information on the relationship between transmission and host population density.

A thorough understanding of the relationship between transmission and host density is also needed for the effective management of infectious diseases. Eradication of any infectious disease from a population requires reducing the effective reproductive number $R_{\mathrm{e}}$ to below one at very low disease prevalence. In almost all situations, this requires driving the basic reproductive number $R_{0}$ (the mean number of secondary infections per primary infection in a fully susceptible population) to below one (Anderson and May 1991, Roberts 2007). Thus, estimating $R_{0}$ has been an essential component of managing recent disease threats, whether to human populations (for example, SARS [Anderson et al. 2004]) or to livestock (for example, foot and mouth disease [Ferguson et al. 2001]). To evaluate the feasibility of potential control strategies such as vaccination or disease suppression by culling of infected animals, it is critical to estimate $R_{0}$ in field situations and to determine how it might be affected by host density or population size. Estimating $R_{0}$ and understanding transmission dynamics in wildlife present a range of challenges beyond those in domestic animal or human populations. All individuals cannot be counted or examined, and contact tracing, as was done with SARS (Lipsitch et al. 2003), is essentially impossible. It is not surprising, therefore, that few estimates of $R_{0}$ in wildlife exist for any disease of importance for conservation (LloydSmith et al. 2005, Real and Biek 2007).

In this paper, we use data derived from extensive mark-recapture studies at a number of sites throughout Tasmania to derive estimates of disease prevalence and the basic reproductive number, and to investigate the role of host density in disease transmission. This information is combined with previously published estimates of demographic parameters (Lachish et al. 2007, 2009) to develop simple deterministic SEI models to evaluate the likelihood of this disease leading to the extinction of the Tasmanian devil. By explicitly considering transmission dynamics, this approach provides a more reliable prognosis of extinction than the extrapolations of observed trends in McCallum et al. (2007) and Lachish et al. (2007).

\section{Methods \\ Trapping and data collection}

Tasmanian devils were trapped at six sites, shown on Fig. 1. One site, Freycinet, was trapped from 1999 onward as part of a life history study by M. E. Jones and students, with disease first detected in the area in 2001 (Lachish et al. 2007). A second site, Fentonbury, was trapped from just prior to any evidence of disease emergence. A third site, Wisedale, was first trapped in 2006, soon after local disease emergence: disease was 
known to be present south of the site (Hawkins et al. 2006), but had not been detected $8 \mathrm{~km}$ north of the site in 2 years of trapping from 2004 (C. Hawkins and R. Hamede, personal observations). At the three remaining sites, Mt William, Bronte Park, and Buckland, disease was well established at the time trapping commenced, although a three-year mark-recapture study had been undertaken at Mt William in the 1980s (Pemberton 1990), well before emergence of the disease. Disease has been present at Mt William since at least 1996. Highquality photographs of DFTD-like signs in devils at Mt William were provided by Christo Baars in 1996 (Hawkins et al. 2006), and DFTD was confirmed in a tumor sampled in 1997 near Waterhouse, $45 \mathrm{~km}$ from Mt William (Loh et al. 2006; T. Knox, personal communication). Devils with DFTD-like signs were caught at Buckland in 1999 (M. E. Jones, unpublished data), though the disease was not confirmed there until 2005. DFTD signs were first observed and confirmed at Bronte in 2003, and our limited understanding of the history of spread of the disease suggests that the disease likely emerged there in 2001 or 2002 (McCallum et al. 2007).

Standardized trapping protocols were followed. At all sites other than Freycinet, 10-night trapping sessions were undertaken with 40-50 traps set over an area of 25-30 km² (see Hawkins et al. 2006). Field work scheduling meant that trapping frequency and timing differed between sites and years: all were sampled between two and four times per annum. At Freycinet, consecutive 7-night trapping sessions were conducted with 25-35 traps set over each of four 35-50 $\mathrm{km}^{2}$ sections comprising the entire $160-\mathrm{km}^{2}$ peninsula (see Lachish et al. 2007). Each section was trapped up to four times per year.

All individuals trapped were individually tagged, using microchip transponders (individual ear tattoos were used prior to 2004 at Freycinet), weighed, sexed, measured, assessed for disease status, and released at the point of capture. Currently, DFTD can only definitively be confirmed through histological examination of a biopsied tumor. The likelihood of an individual having DFTD was therefore scored on the basis of the external morphology of any lumps or lesions found using an index ranging from 1 (no lumps or lesions found), through 2 and 3 (lumps or lesions unlikely to be DFTD), to 4 and 5 (characteristic DFTD tumors present [Hawkins et al. 2006]). Only individuals with lesions or lumps characteristic of DFTD (those that scored 4 or 5) were included as diseased in these analyses.

To examine seasonal trends, we grouped months into summer (late November through February), approximately corresponding to the period in which juveniles become independent and disperse; autumn (March through May), during which mating and birth normally occur; winter (June through August) during which females have large pouch young; and spring (Septem-

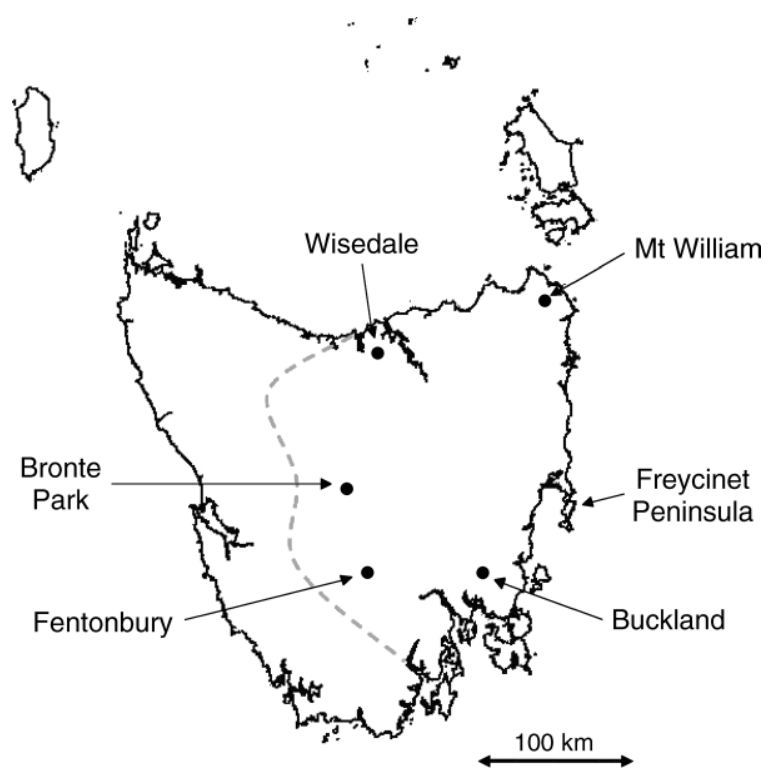

FIG. 1. Map of Tasmania, indicating locations of study sites. The approximate location of the disease front, as of early 2008, is shown with a dashed line (updated from Hawkins et al. [2006] and McCallum et al. [2007]).

ber through early November) when most young are in the den.

\section{Allocation into age classes}

Breeding in Tasmanian devils is seasonal, with half of births occurring in March (the Austral autumn) after a short (3-week) gestation (Hesterman 2008). Pouch vacation, which is functionally equivalent to birth in placentals, occurs 15-16 weeks later (primarily in August). As is typical of marsupials (Cockburn and Johnson 1988), a large proportion of the year is devoted to reproduction, with weaning in devils occurring the following summer between December and February (Hesterman 2008). For the purposes of allocating animals into age classes, all births were assumed to occur on the mean birth date of 20 March each year. Animals were aged to their nearest year-class of birth using molar eruption, tooth wear indices, and canine over-eruption (distance from the dentine-enamel junction to the gum). This method is precise for aging devils to 3 years of age (M. E. Jones, D. Sinn, N. Beeton et al., unpublished manuscript). Accordingly, all animals with estimated ages of three or greater were pooled into a single age category.

\section{Statistical analysis}

Mark-recapture data were analyzed using MARK (Cooch and White 2002). Population size within the 7-10 day trapping trips at each site was estimated using closed population estimates including heterogeneity in capture probabilities with time and between individuals (Chao et al. 1992) implemented in the program CAPTURE (Otis et al. 1978, Rexstad and Burnham 
1992). We also used results from these models to investigate whether the recapture probability within field trips was influenced by infection status. Population size estimates, together with $95 \%$ confidence bounds, were converted to estimates of density by dividing by the area of a minimum convex polygon constructed around the trapping grid, with an additional 2-km boundary strip (Kenward 1985) (representing approximately half the home range diameter of a Tasmanian devil [Pemberton 1990]), unless adjacent to a coastline, in which case the strip was applied only to any land boundaries.

Prevalence data were analyzed using logistic models implemented in R (version 2.6.1, R Development Core Team 2007). Because the residual deviance in logistic models suggested overdispersion, we used generalized mixed models, implemented using the function lmer in $\mathrm{R}$ package lme4, with the field trip-age class interaction as a random error term. As predictor variables, we explored age class (1-2, 2-3, 3+ years), season (austral winter, spring, summer, autumn), and trend (years from the first appearance of disease, or the start of the data set, whichever was later). We fitted models using all possible combinations of main effects and up to twoway interactions. We also explored models with aggregated versions of age class $(1-2,2+)$ and season (summer, other seasons), again with all possible combinations of main effects and up to two-way interactions. For each model, we calculated small sample corrected Akaike Information Criteria $\left(\mathrm{AIC}_{\mathrm{c}}\right)$ and Akaike weights (see Burnham and Anderson 2004).

\section{Estimation of $R_{0}$}

We approximated the basic reproductive number $R_{0}$ from $r_{0}$, the rate of increase in prevalence per unit time following the first introduction of disease into the population using Eq. 1 ( $R_{0}^{+}$in Roberts and Heesterbeek 2007)

$$
R_{0}=\exp \left(r_{0} T\right)
$$

where $T$ is the mean generation time of the disease or serial interval (i.e., the average time between acquisition of infection and the infection being passed on to another individual). This is the sum of the incubation period and the time from the disease becoming detectable to first transmission. In the absence of accurate information on the latent period, other than the single anecdotal report of 10 months, we explored a plausible range of generation times of between 3 and 12 months. The trend parameter, from logistic regression models of prevalence following the first detection of disease at the two sites (Freycinet and Fentonbury) that were trapped from the time of first disease onset, provided an estimate of $r_{0}$.

\section{Models of transmission dynamics}

To investigate whether the observed changes in disease prevalence and population density through time were consistent with either frequency-dependent or density-dependent disease transmission, we constructed a simple deterministic SEI (Susceptible, Exposed, Infectious) model with annual age classes, based on devil life history parameters estimated in Lachish et al. (2007). Transmission was parameterized to match the initial increases in prevalence observed at Fentonbury in this present study, and only animals older than one were assumed susceptible (see Hawkins et al. 2006, Lachish et al. 2007). In this simplified model, transitions through age classes and from exposed to infectious classes are assumed to occur at constant rates. The equations used were as follows:

$$
\begin{aligned}
& \frac{d S_{0}}{d t}=\left(\sum_{i} b_{i} N_{i}\right)(1-N)-\mu_{0} S_{0}-f(I, N) S_{0}-S_{1} \\
& \frac{d S_{i}}{d t}=-\mu_{i} S_{i}-f(I, N) S_{i}+S_{i-1}-S_{i} \quad \text { for } i>0 \\
& \frac{d E_{i}}{d t}= \begin{cases}f(I, N) S_{0}-\left(\mu_{i}+d\right) E_{i}-E_{i} & \text { for } i=0 \\
f(I, N) S_{0}+E_{i-1}-\left(\mu_{i}+d\right) E_{i}-E_{i} & \text { for } i>0\end{cases}
\end{aligned}
$$

$$
\frac{d I_{i}}{d t}= \begin{cases}d E_{i}-\left(\mu_{i}+\alpha\right) I_{i}-I_{i} & \text { for } i=0 \\ d E_{i}-\left(\mu_{i}+\alpha\right) I_{i}+I_{i-1}-I_{i} & \text { for } i>0 .\end{cases}
$$

Here, $i$ represents age class $(0,1,2, \ldots)$. The variables $S_{i}$, $E_{i}, I_{i}$, and $N_{i}$ represent susceptible, exposed, infectious, and total numbers of devils of age $i$ (all scaled relative to the carrying capacity) with $I$ and $N$ representing totals across age classes. The parameters are: $b_{i}$, age-specific birth rates; $\mu_{i}$, age-specific disease-independent mortality rates; $d$, the rate of transition from exposed to infectious age classes; and $\alpha$, the increment in death rate caused by symptomatic disease. Transmission is modeled by the function $f(I, N)$, which is $\beta I$ for density-dependent transmission and $\beta I / N$ for frequency-dependent transmission.

\section{Results}

\section{Effects of DFTD infection on capture probability}

There was no evidence that infection status had any effect on capture probability within field trips. We compared closed population models in which capture probability was constant with models in which capture probability varied between infected and uninfected devils at Bronte (13 trapping sessions), Fentonbury (12 trapping sessions), and Freycinet (7 trapping sessions). In none of these 32 sessions did AIC values indicate that a model with separate capture probability for infected and uninfected devils was preferred, and in each case the 95\% confidence interval for the difference in capture probability included 0 . There were 13 sessions in which the estimated capture probability was higher for healthy animals and 19 in which the estimated capture probability was higher for diseased animals $(P=0.38$ for $H_{0}$ of equal capture probability, exact binomial test). 
TABLE 1. The influence of host sex on disease prevalence at six sites.

\begin{tabular}{lrrccrr}
\hline \hline \multicolumn{1}{c}{ Site } & $\begin{array}{c}\mathrm{AIC}_{\mathrm{c}} \\
(-\mathrm{sex})\end{array}$ & $\begin{array}{c}\mathrm{AIC}_{\mathrm{c}} \\
(+\mathrm{sex})\end{array}$ & $\begin{array}{c}\mathrm{AIC}_{\mathrm{c}} \\
\text { weight }(- \text { sex })\end{array}$ & $\begin{array}{c}\mathrm{AIC}_{\mathrm{c}} \\
\text { weight }(+ \text { sex })\end{array}$ & $\begin{array}{c}\text { M:F } \\
\text { log-odds ratio }\end{array}$ & $\mathrm{SE}$ \\
\hline Fentonbury & 159.91 & 163.13 & 0.83 & 0.17 & 0.0591 & 0.326 \\
Wisedale & 107.77 & 111.12 & 0.84 & 0.16 & 0.117 & 0.413 \\
Bronte & 112.64 & 112.28 & 0.46 & 0.54 & -0.835 & 0.409 \\
Buckland & 77.50 & 81.81 & $0.71 \dagger$ & 0.03 & -0.118 & 0.487 \\
Mt William & 117.43 & 119.64 & $0.49 \ddagger$ & 0.16 & 0.580 & 0.427 \\
Freycinet & 236.49 & 238.80 & 0.76 & 0.24 & 0.242 & 0.253 \\
\hline
\end{tabular}

Note: $\mathrm{AIC}_{\mathrm{c}}$ and $\mathrm{AIC}_{\mathrm{c}}$ weights for models including additive effects of field trip and age class, with and without a sex effect, are shown, together with the estimated log-odds ratio (and standard error) of being infected for males (M) relative to females (F).

$\uparrow \mathrm{AIC}_{\mathrm{c}}$ weight for model with only age class is 0.25 .

$+\mathrm{AIC}_{\mathrm{c}}$ weight for model with only age class is 0.35 .

We have therefore treated prevalence of disease in the trapped population as an unbiased estimate of prevalence in the population as a whole.

\section{Prevalence in males and females}

There was no evidence of consistent differences in disease prevalence between males and females. Table 1 shows results of adding a sex effect to logistic models predicting prevalence from field trip (which encompasses possible trend and season effects) and age class. At one site (Bronte) the $\mathrm{AIC}_{\mathrm{c}}$ weight of the model including sex was slightly greater than that of the model without the sex effect. At all other sites, the $\mathrm{AIC}_{\mathrm{c}}$ weight of models without a sex effect was substantially greater. Models including an interaction between sex and field trip were not supported at any site. At four of the six sites, the logodds of being infected were greater in males than in females, with the reverse being the case at the other two sites. Estimated odds ratios for the sex effect were small at four of the six sites, with a marginally significant $(P=$ 0.04 ) female bias in infection at Bronte and a substantial (but insignificant) point estimate of male bias in infection at Mt William.

\section{Increases in prevalence following disease invasion}

Fig. 2A, D, G shows the prevalence of DFTD in all animals older than 1 year captured at Freycinet. No diseased animals $<1$ year old were observed. Table 2 summarizes the results of generalized mixed models based on these data. There are four models with similar support, each including trend and an age effect on prevalence. Three of these contrast 1-2-year-olds with older animals. There is also some evidence that the rate of increase in prevalence may differ between age classes, with three of the four most strongly supported models including an interaction between age and trend. Evidence for a seasonal effect is weaker. Prevalence is lower in 1-2-year-olds than in older animals (Fig. 2).

Fig. 2B, E, H shows the increase in prevalence of DFTD since its arrival at Fentonbury. There is strong support for models including both trend and contrasting 1-2-year-olds with older animals (see Table 2), as was the case at Freycinet. However, there is also strong support for a seasonal influence on prevalence, with all the well-supported models including a term that contrasts summer with the other three seasons. As with Freycinet, the best-supported model suggested that the rate of increase in prevalence differed with age.

Interpretation of the results at Wisedale was hampered both by the short run of data ( 2 years) and also by the fact that prevalence was at $>30 \%$ in $3+$ year-olds at the time of the first survey (Fig. 2). Nevertheless, there is strong support for an increase in prevalence through time and of higher prevalence in adults $(2$ years +$)$ compared with 1-2-year-olds. However, there was no evidence of seasonality at this site (Table 2).

There was strong support for a model in which the rate of increase in prevalence among 2-3-year-old animals differed between the three sites, but weak support for models including seasonality (Table 3). Inspection of the parameter estimates and 95\% posterior density intervals for the best-supported model (Table 4) suggests that prevalence increased more slowly at Freycinet than at Fentonbury. (The interval for the trend: Freycinet interaction does not include zero.)

\section{Prevalence at sites where disease was established}

The Bronte, Buckland, and Mt William sites each had disease well established at the time of the first survey, with estimated prevalence in excess of 50\% in 2-3-yearolds (Fig. 3). At Bronte and Buckland, there was no evidence of a trend in prevalence with time (Table 5). However, at Mt William, despite the fact that disease had been present in this population for at least eight years when surveys commenced, there was strong support for an increase in prevalence with time. At both Mt William and Bronte, there was strong support for models in which prevalence differed between age classes (either all three age classes or 1-2-year-olds vs. older animals) and with season, with evidence of an interaction between the two factors at Mt William. At Buckland, which had the least data, the null model (no effect of season, age class, or trend) was most strongly supported.

\section{Seasonality}

Fig. 4 shows parameter estimates for the effect of season (relative to summer) on prevalence in 1-2-year-old 
Freycinet
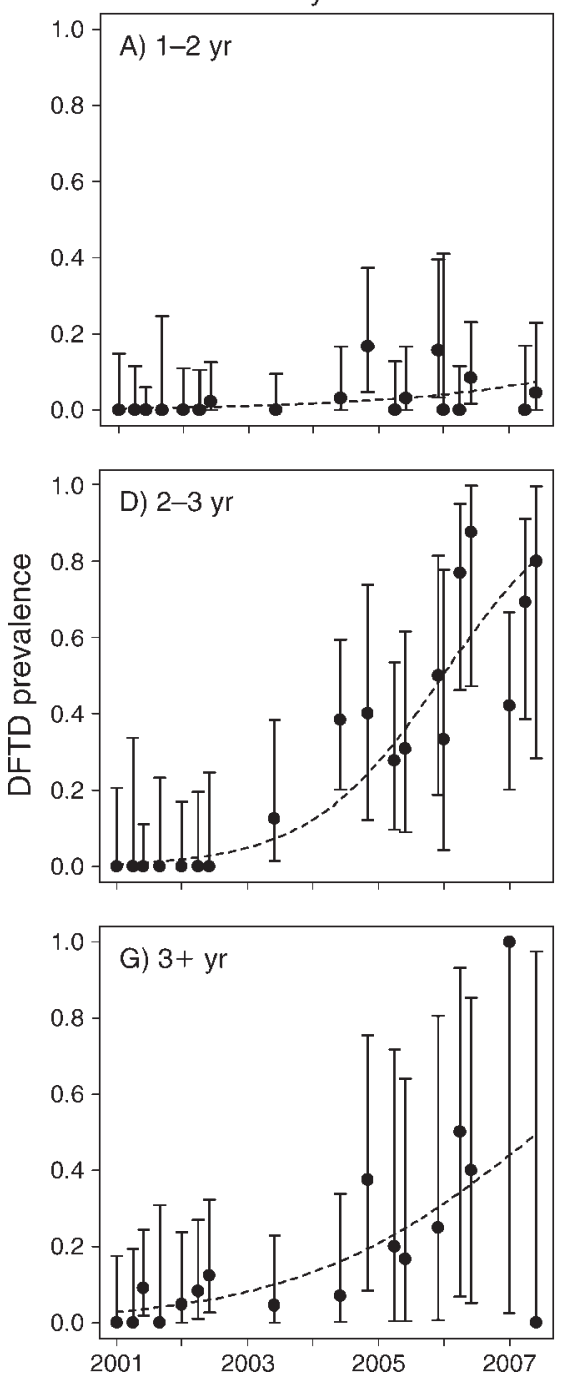

Fentonbury
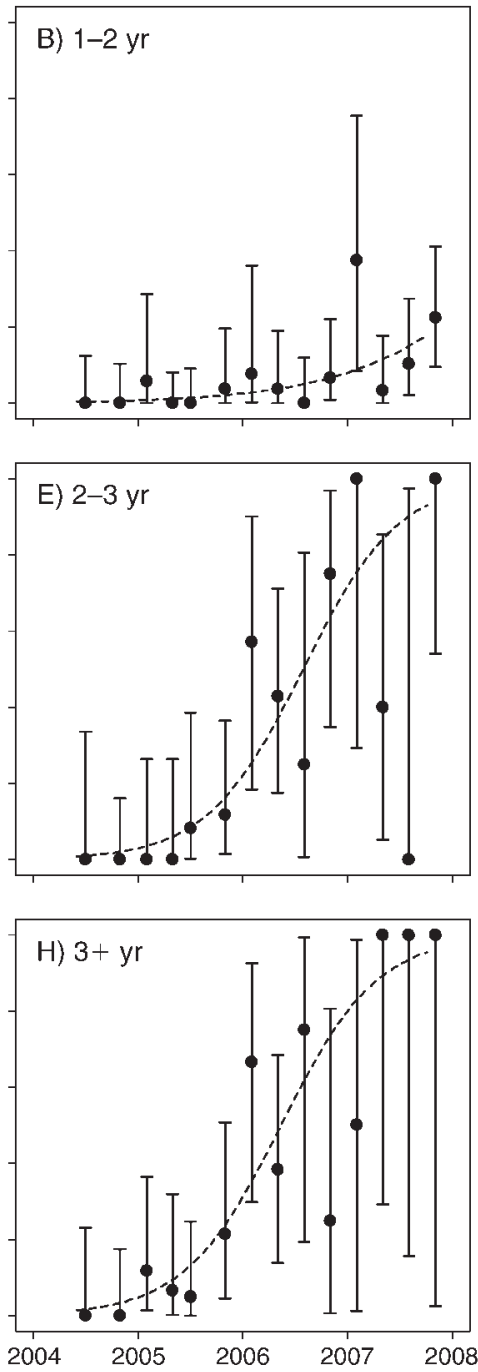

Wisedale
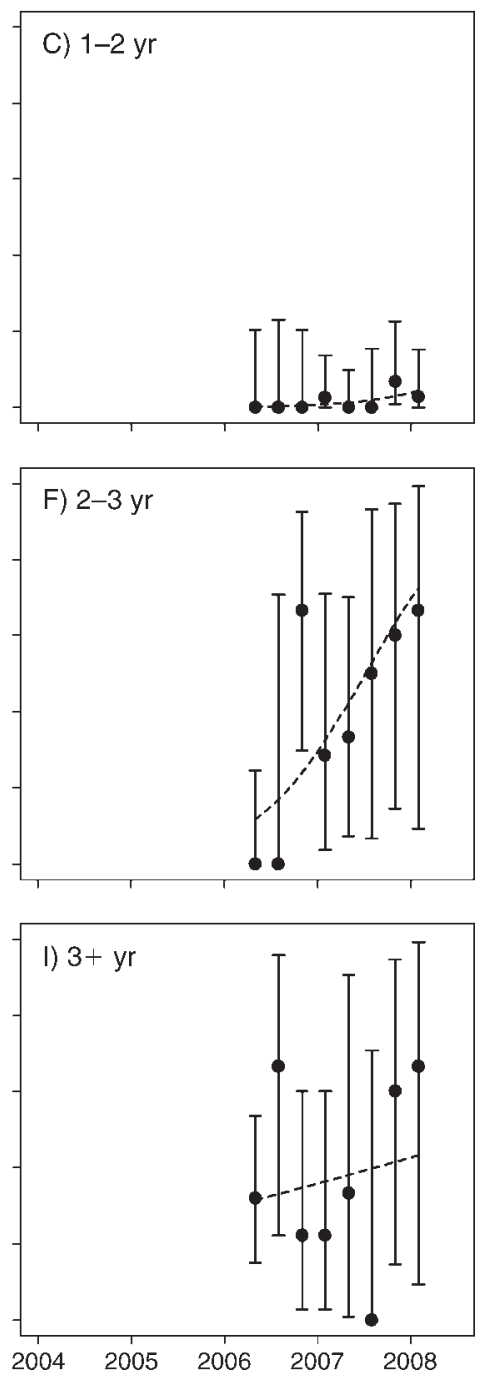

FIG. 2. Prevalence of Tasmanian devil facial tumor disease (DFTD) at three sites: Freycinet (A, D, and G), Fentonbury (B, E, and $\mathrm{H}$ ), and Wisedale $(\mathrm{C}, \mathrm{F}$, and I), monitored from before or close to the onset of disease. (A-C) Tasmanian devils from 1-2 years of age, (D-F) devils 2-3 years of age, (G-I) devils 3+ years of age. Error bars are 95\% exact binomial confidence intervals, and the dashed lines represent the best fit of a logistic regression model including age class and trend but without seasonal effects.

and 2-3-year-old devils, for all season-site combinations in which the effects were estimable. Effects are corrected for trend in those sites where it was well supported in the previous analysis (Fentonbury, Wisedale, Freycinet, and Mt William). Effects of season are strongly negative in one-year-olds in autumn (immediately after their presumed birthday), but then appear to decrease in magnitude through the year. There is no evidence of consistent seasonality across sites in two-year-olds.

\section{Impacts on devil population size}

At all sites, except Buckland and Wisedale, the estimated devil population size declined in the presence of the disease (Fig. 5, Table 6). There was no evidence that disease prevalence in adult devils declined with population size, as would be expected if transmission were density dependent.

\section{Estimates of $R_{0}$}

Table 7 shows estimates of $R_{0}$ based on the Freycinet and Fentonbury models reported above. Estimates for Freycinet are considerably lower than those at Fentonbury for the same serial interval. The extreme influence of the generation time estimate on $R_{0}$ is also evident.

\section{Alternate models of disease transmission}

Fig. 6 shows trajectories of devil density and DFTD prevalence predicted from both density-dependent and frequency-dependent transmission for a range of plausible latent periods. With frequency-dependent trans- 
TABLE 2. Generalized mixed models of Tasmanian devil facial tumor disease prevalence at three sites, where monitoring commenced close to DFTD arrival.

\begin{tabular}{lrrc}
\hline \hline \multicolumn{1}{c}{ Model terms } & $\begin{array}{c}\text { Param- } \\
\text { eters }\end{array}$ & $\Delta \mathrm{AIC}_{\mathrm{c}}$ & $\begin{array}{c}\text { Akaike } \\
\text { weight, } w_{i}\end{array}$ \\
\hline Freycinet $(N=54)$ & & & \\
Ad.juv $\times$ trend & 5 & 0.00 & 0.196 \\
Ad.juv + trend & 4 & 0.40 & 0.160 \\
Age class $\times$ trend & 7 & 0.49 & 0.153 \\
Ad.juv $\times$ (trend + season $)$ & 11 & 0.56 & 0.147 \\
Ad.juv $\times$ trend + summer & 6 & 2.18 & 0.066 \\
Age class + trend & 5 & 2.48 & 0.056 \\
Age class $\times$ trend + summer & 8 & 2.48 & 0.056 \\
Ad.juv + trend + summer & 5 & 2.62 & 0.053 \\
Fentonbury $(N=42)$ & & & \\
Ad.juv $\times$ trend + summer & 6 & 0.00 & 0.359 \\
Ad.juv $\times$ summer + trend & 6 & 1.24 & 0.194 \\
Ad.juv + trend + summer & 5 & 1.61 & 0.161 \\
Ad.juv $\times$ (trend + summer $)$ & 7 & 1.89 & 0.140 \\
Wisedale $(N=24)$ & & & \\
Ad.juv + trend & 4 & 0.00 & 0.479 \\
Ad.juv & 3 & 2.76 & 0.121 \\
Ad.juv $\times$ trend & 5 & 2.87 & 0.114 \\
\hline
\end{tabular}

Notes: Age class represents three age classes, 1-2-year-olds, 2-3-year-olds, and 3+ year-olds; trend is time in years since disease emergence at the site; season is the four Austral seasons; ad.juv is age class contrasting 1-2-year-olds vs. older animals, and "summer" contrasts summer with the remaining seasons. A "+" represents additive effects, whereas a " $X$ " also includes interactions. Models for each site are shown in order of increasing $\mathrm{AIC}_{\mathrm{c}}$ (small-sample corrected Akaike Information Criterion). All possible models including up to two-way interactions were fitted, but only models with a difference in $\mathrm{AIC}_{\mathrm{c}}$ from the best model $(\Delta \mathrm{AIC})$ of $<3$ are shown. The table also presents the Akaike weight $w$ of these plausible models (calculated relative to all the models fitted for that site). This can be considered as the weight of evidence in support of the model or (loosely) as the probability that the model is the best of those considered for the data (Burnham and Anderson 2004). Also shown is the number of parameters for each model and the sample size $N$ (trip-age class combinations) at each site.

mission, the model predicted the maintenance of high prevalence levels in populations where devil density has declined substantially after several years since disease introduction, consistent with our field observations (Fig. 6). The model predicts devil decline to infinitesimal levels, which would correspond to host extinction in any finite population. The equilibrium prevalence is higher for shorter latent periods. The same model formulated with density-dependent transmission was unable to generate high levels of DFTD prevalence with decreasing population abundance, whatever the latent period, and predicts maintenance of devil numbers at around $40 \%$ of the original carrying capacity, with oscillations in host numbers damping more rapidly as the latent period increases. As is predicted by simpler, nonstructured models (de Castro and Bolker 2005), the two transmission modes thus produce very different outcomes, with a stable equilibrium between host and pathogen generated from density-dependent transmission, but with host extinction predicted from frequencydependent transmission.
TABLE 3. Generalized mixed models comparing increases in prevalence with time in 2-3-year-old Tasmanian devils at Freycinet, Fentonbury, and Wisedale.

\begin{tabular}{lccc}
\hline \multicolumn{1}{c}{ Model terms } & Parameters & $\Delta \mathrm{AIC}_{\mathrm{c}}$ & $w_{i}$ \\
\hline Site $\times$ trend & 7 & 0.00 & 0.560 \\
Site + trend & 5 & 2.07 & 0.199 \\
Site $\times$ trend + summer & 8 & 3.01 & 0.124 \\
Site $\times$ (summer + trend $)$ & 10 & 4.44 & 0.061 \\
Site + trend + summer & 6 & 4.74 & 0.052 \\
\hline
\end{tabular}

\section{Discussion}

Prevalence of DFTD is very high in 2-3-year-old individuals at all sites, once disease has been present in the area for several years. Given that the disease is typically fatal within six months of the first appearance of a visible tumor (Hawkins et al. 2006), infection levels in excess of 50\% in all 2-3-year-olds present at any given time mean that the disease is having a devastating impact on Tasmanian devil populations. This can be seen from the ongoing population declines at almost all sites when disease is present (see Fig. 5). The lack of significant declines in population size following DFTD introduction at Wisedale and Buckland is likely to be an artifact of the short time-series available for these two sites. Further analysis of trapping data from all sites (Jones et al. 2008) shows a total change in the life history of Tasmanian devils in diseased populations, with an almost complete disappearance of animals older than three years of age.

Particularly concerning is the lack of evidence of any substantial decrease in prevalence in populations such as Mt William, in which the disease has been established for lengthy periods, despite the overall population size being reduced by as much as 90\% since 1996 (based on estimates from spotlighting counts [McCallum et al. 2007]). Comparison of Figs. 2 and 3 suggests that prevalence in $2-3$-year-olds is at least $50 \%$ in populations where the disease is well established, but may reach $80 \%$ or more within four years of disease arrival. However, prevalence in 1-2-year-old animals appears to be greater in the populations where disease is established than it is in the populations monitored early after the arrival of the disease.

TABLE 4. Parameter estimates for the most strongly supported model (site $\times$ trend) of the prevalence of Tasmanian devil facial tumor disease in 2-3-year-old devils at three sites.

\begin{tabular}{lrrr}
\hline \hline \multicolumn{1}{c}{ Parameter } & Estimate & Lower & Upper \\
\hline Intercept & -5.879 & -8.720 & -3.920 \\
Freycinet & 0.836 & -2.156 & 3.904 \\
Wisedale & 3.057 & -0.115 & 6.616 \\
Trend & 2.268 & 1.450 & 3.483 \\
Freycinet : trend & -1.254 & -2.464 & -0.301 \\
Wisedale : trend & -0.413 & -2.411 & 1.692
\end{tabular}

Notes: Site effects are relative to Fentonbury. Lower and upper 95\% confidence bounds were derived from Highest Posterior Density intervals from a Markov chain Monte Carlo sample $(n=50000)$. 
Bronte

A) $1-2 \mathrm{yr}$

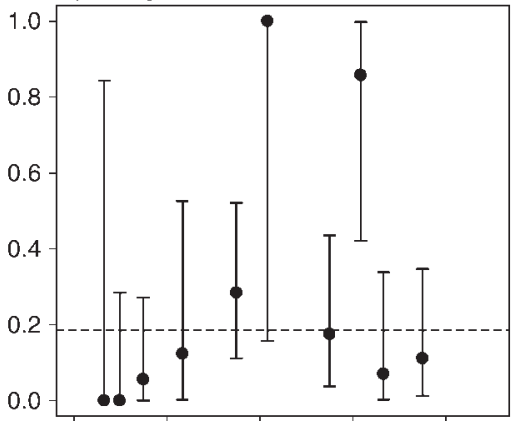

D) 2-3 yr

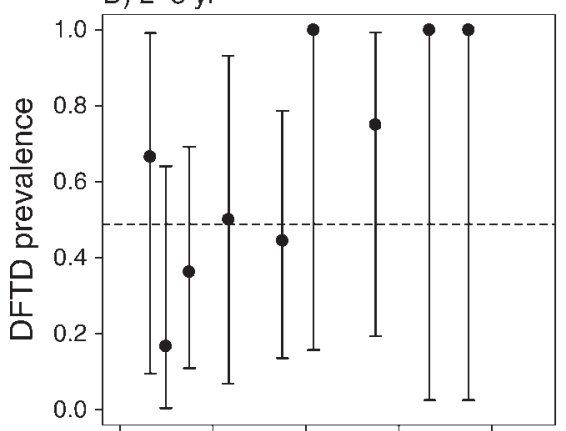

G) $3+y r$

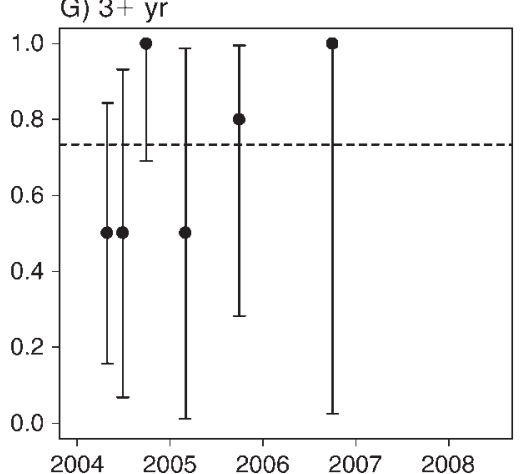

Mt William

B) $1-2 \mathrm{yr}$

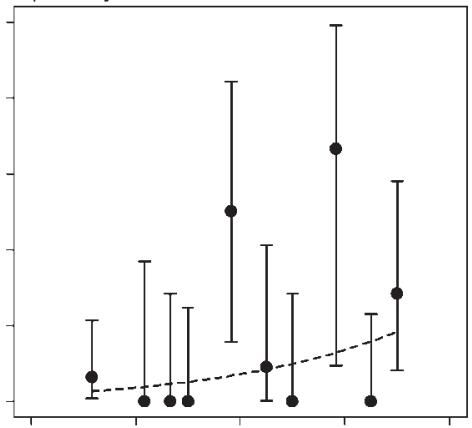

E) $2-3 \mathrm{yr}$

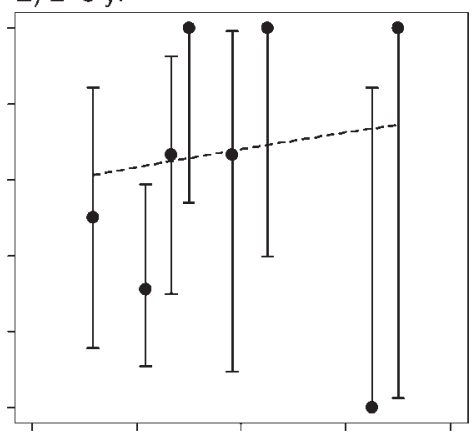

H) $3+y r$

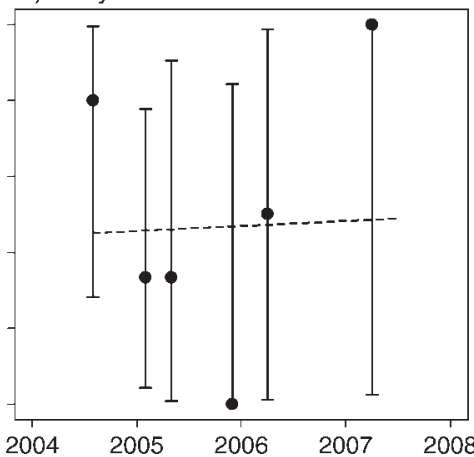

Buckland



F) 2-3 yr
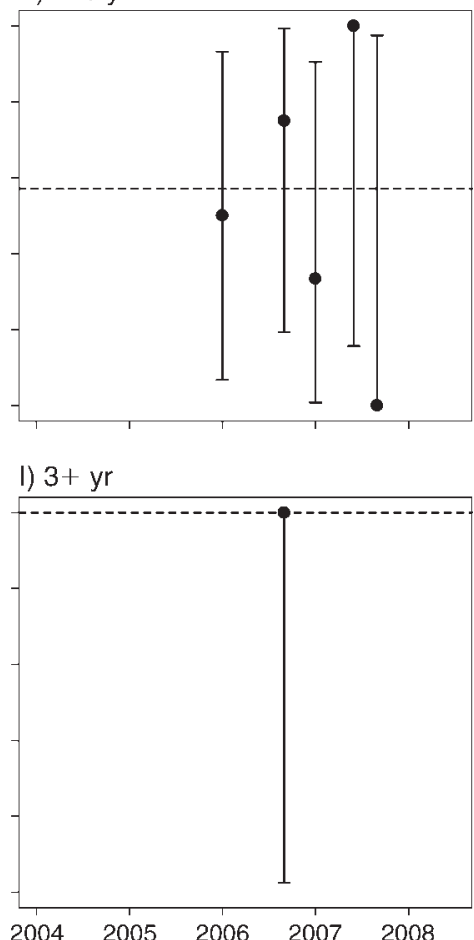

FIG. 3. Prevalence of DFTD at three sites where monitoring began well after disease was established: Bronte (A, D, and G), Mt William (B, E, and H), and Buckland (C, F, and I). (A-C) Tasmanian devils 1-2 years of age, (D-F) devils 2-3 years of age, (G-I) devils $3+$ years of age. Error bars are $95 \%$ exact binomial confidence intervals. The dashed lines in the Mt William panels represent the best fit of a logistic regression model including age class and trend but without seasonal effects. As there was no evidence of a trend at the other two sites, the dashed lines at the other two sites represent the mean prevalence in that age class across all sampling intervals.

The very high levels of prevalence reached and maintained in 2-3-year-olds indicate that transmission depends weakly, if at all, on host density, and shows no evidence of any threshold population density below which the disease cannot be maintained within the Tasmanian devil population. Our simple age-structured model suggests that the high levels of prevalence maintained even after large population declines are inconsistent with the hypothesis of density-dependent disease transmission, but are more consistent with transmission being dependent on the frequency of infected hosts in the population. The predicted preva- lence for frequency-dependent transmission if a 3-month latent period is assumed is close to the observed prevalence. However, the simplified way in which time delays are modeled in Eqs. 2-5 limits the extent to which the quantitative predictions of prevalence from the model can be directly compared with those observed in Figs. 2 and 3. In the absence of a threshold population density for disease maintenance, it is theoretically possible for a host-specific pathogen such as DFTD to lead to host extinction (de Castro and Bolker 2005).

Substantial reductions in population size following disease epidemics may cause density-dependent com- 
TABLE 5. Generalized mixed models of Tasmanian Devil facial tumor disease prevalence at three sites, at which disease was well established when monitoring commenced.

\begin{tabular}{lccc}
\hline \hline \multicolumn{1}{c}{ Model terms } & Parameters & $\Delta \mathrm{AIC}_{\mathrm{c}}$ & $w_{i}$ \\
\hline Mt William $(N=44)$ & & & \\
Ad.juv $\times$ season + trend & 8 & 0.00 & 0.346 \\
Ad.juv & 3 & 2.50 & 0.099 \\
Ad.juv $\times$ (trend + season $)$ & 9 & 2.67 & 0.091 \\
Ad.juv $\times$ season & 7 & 2.79 & 0.086 \\
Bronte Park $(N=25)$ & & & \\
Age class + season & 7 & 0.00 & 0.228 \\
Age class + summer & 5 & 0.84 & 0.150 \\
Ad.juv + summer & 4 & 1.00 & 0.138 \\
Age class + summer + trend & 6 & 1.12 & 0.130 \\
Ad.juv + season & 6 & 1.35 & 0.116 \\
Ad.juv + summer + trend & 5 & 1.99 & 0.084 \\
Buckland $(N=11)$ & & & \\
Null & 2 & 0.00 & 0.400 \\
Ad.juv & 3 & 1.48 & 0.191 \\
Trend & 3 & 1.50 & 0.189
\end{tabular}

Notes: As in Table 2, age class represents three age classes, 12 -year-olds, 2-3-year-olds, and 3+ year-olds; trend is time in years since disease emergence at the site; season is the four Austral seasons; ad.juv is age class contrasting 1-2-year-olds vs. older animals, and "summer" contrasts summer with the remaining seasons. A "+" represents additive effects, whereas a " $X$ " also includes interactions. Models for each site are shown in order of increasing $\mathrm{AIC}_{\mathrm{c}}$ (small-sample corrected Akaike Information Criterion). All possible models including up to two-way interactions were fitted, but only models with a difference in $\mathrm{AIC}_{\mathrm{c}}$ from the best model $\left(\Delta \mathrm{AIC}_{\mathrm{c}}\right)$ of $<3$ are shown. At both Bronte Park and Buckland, the data were too sparse for models including interactions with age class and season or summer to be fitted. The table presents the Akaike weight $w$ of these plausible models (calculated relative to all the models fitted for that site). Also shown is the number of parameters for each model and $N$, the sample size (trip-age class combinations) at each site.

pensatory changes in host population dynamics, mediated via changes to the life history traits of individuals, which can potentially mitigate the population decline (Fowler 1981). In areas where DFTD has become established, there is evidence of increased breeding in females between one and two years of age. (Prior to the disease the majority of female devils began breeding at two years of age [Jones et al. 2008].) Widespread precocial breeding in Tasmanian devils, however, is precluded by physiological and ecological constraints that limit the ability of one-year-olds to breed (Lachish et al. 2009). Since no other compensatory responses to population decline have been observed (Lachish et al. 2009), the observed reproductive compensation will be unlikely to greatly alter a population's trajectory once disease is established. Further, the frequency-dependent transmission described in this paper, together with the observation that bite injuries are particularly prevalent in the mating season (Hamede et al. 2008) suggest that DFTD has some attributes of a sexually transmitted disease. Precocial breeding might therefore be associated with increased disease in young animals. (Compare Figs. 2 and 3 for DFTD prevalence in 1-2-year-olds.)
Transmission is the key process in the dynamics of an infectious disease, but is invariably the most difficult process to parameterize, particularly in an emerging disease of wildlife. DFTD is no exception. In both of the sites from which we have good data from the time of the first appearance of the disease (or very soon thereafter), the disease is initially at higher prevalence in older animals than in younger animals. This would be expected given that there appears to be a substantial incubation period and that bite injuries occur more frequently in adults than in subadults (Hamede et al. 2008). Increased prevalence in older age classes is expected in most diseases that produce persistent infections, simply because older animals have had more time to become infected (Grenfell and Anderson 1985). In the case of DFTD, however, infected animals are removed from the population within $\sim 6$ months because the disease is invariably lethal, meaning that the
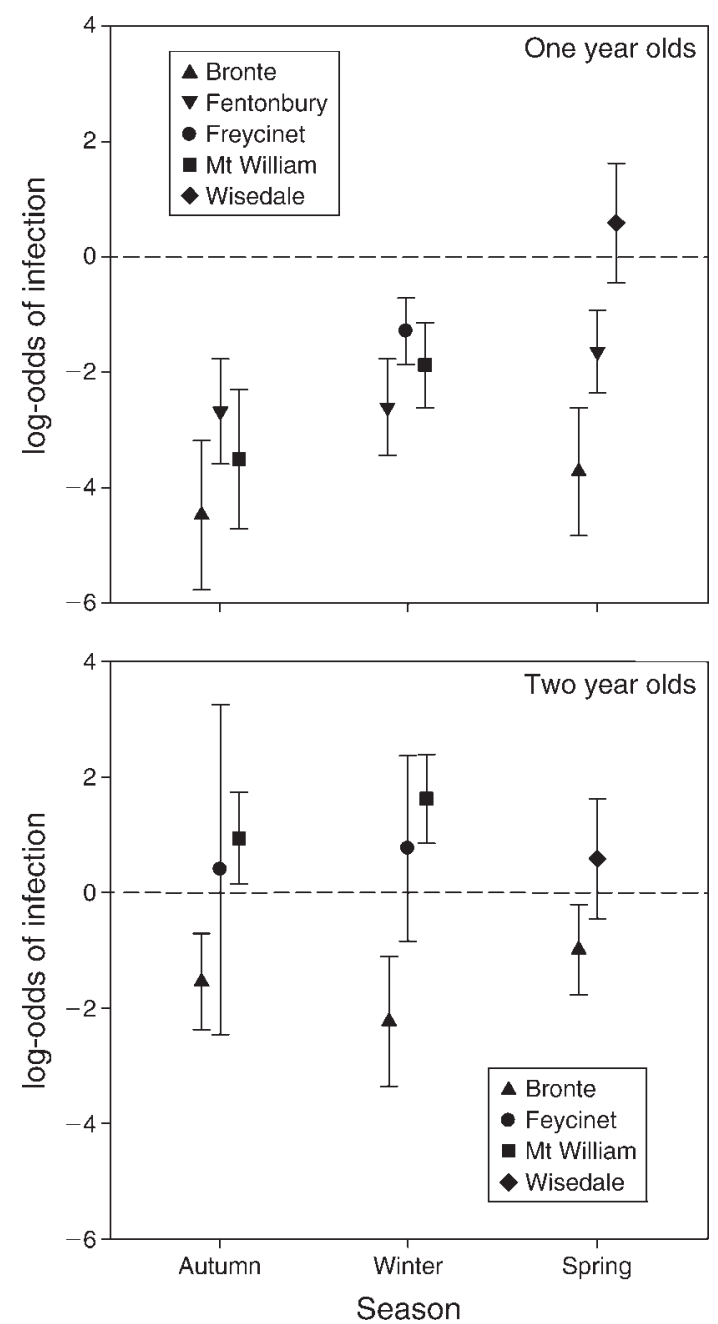

FIG. 4. Estimates of effects of season (relative to summer) on log-odds of infection, with standard errors. Bronte, uppointing triangles; Fentonbury, down-pointing triangles; Freycinet, circles; Mt William, squares; Wisedale, diamonds. 

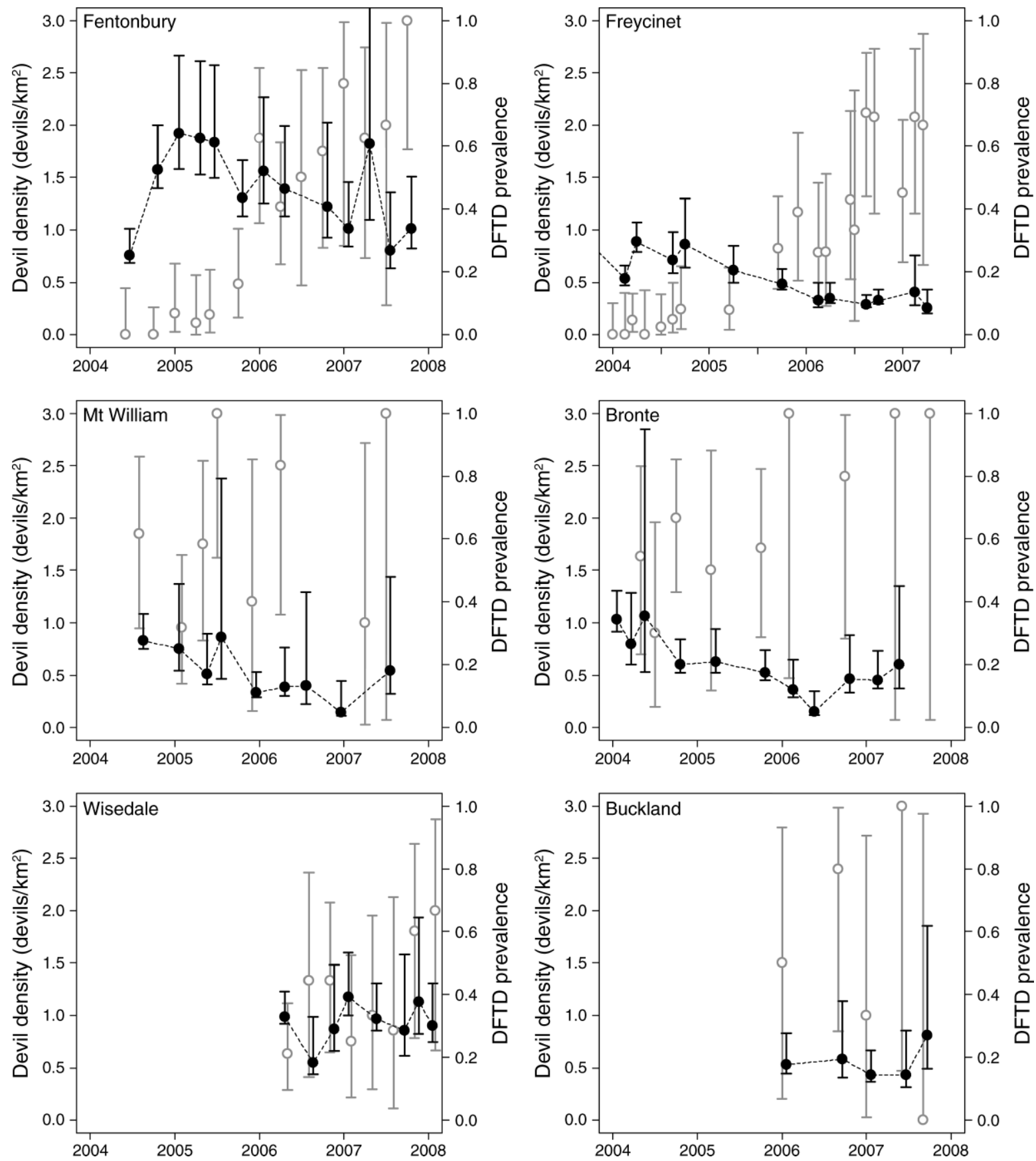

FIG. 5. Estimates of population density (devils $/ \mathrm{km}^{2}$, with $95 \%$ confidence intervals; black lines and solid symbols) of Tasmanian devils at the six study sites. The prevalence of DFTD in adult animals (2 years and older; with exact binomial 95\% confidence intervals; gray lines and open symbols), is also shown, with scale numbers on the right axis of each panel. Note that data from 2001 are included in the graph for Freycinet.

predicted relationship between age and prevalence is not as straightforward.

While there is evidence of a seasonal pattern in prevalence in one-year-olds at most sites (see Fig. 4), this probably does not represent a seasonal pattern in transmission. Devils are born over a 6-month period, although half of births occur in March (Hesterman
2008). This means that "1-2-year-olds" sampled in autumn have probably just passed their first birthday, and have only been weaned for 3-4 months, whereas 12 -year-olds sampled in summer are nearly two. The diminishing effect on prevalence of season relative to summer in 1-2-year-olds in Fig. 4 is therefore most likely simply a function of longer potential exposure of 
TABLE 6. Trends in Tasmanian devil population density at six sites when disease was present.

\begin{tabular}{lrcll}
\hline \hline \multicolumn{1}{c}{ Site } & df & $b$ & SE $(b)$ & $P$ \\
\hline Freycinet & 10 & -0.163 & 0.0266 & 0.0001 \\
Fentonbury & 9 & -0.259 & 0.0487 & 0.0004 \\
Wisedale & 6 & 0.010 & 0.112 & 0.927 \\
Mt William & 7 & -0.5511 & 0.1148 & 0.0020 \\
Bronte & 9 & -0.3403 & 0.1089 & 0.012 \\
Buckland & 3 & -0.0865 & 0.1515 & 0.608
\end{tabular}

Note: The trend parameter $(b)$ is shown together with its standard error and significance, derived from a regression of $\ln$ (population density) vs. time in years, weighted by the estimated density divided by the square of the width of the confidence interval.

those animals to infection. The lack of a similar pattern in 2-3-year-olds suggests that a seasonal effect is not due to a seasonal change in the force of infection. This is a rather unexpected result. The most likely means of disease transmission is through biting, and there is evidence that, in adults, biting injuries are typically around twice as common during the mating season (March) as in other seasons (Hamede et al. 2008). An increase in disease prevalence would therefore be expected following a lag equal to the average incubation period, particularly as infections progress from first detection to death within six months. One explanation for the lack of a seasonal peak in prevalence is that the incubation period may be variable between individual infections, depending on a range of factors, which might include the number of infected cells transferred, the location of the transfer, and the genotype and immunological status of the infected host. Another factor that may act to distribute any seasonal peak in transmission detectable through prevalence is that in this analysis, early- and late-stage infections are not distinguished.

The estimates of $R_{0}$ reported here differ substantially between the two areas from which they were derived, being significantly higher at Fentonbury than at Freycinet (see Table 7). This is to be expected: $R_{0}$ is not an intrinsic property of a disease, but depends on the environment in which the disease occurs, and also may depend on population density. The estimated population density at Fentonbury was indeed higher than at Freycinet at the time of disease arrival (see Fig. $5)$. However, the very high prevalence in adult ( $2+$ years) devils maintained at all sites, despite major declines in density, suggests that transmission depends weakly on population density. A contributor to the higher rate of increase in prevalence with time at Fentonbury compared with Freycinet is likely to be the different physical properties of the two study areas. Freycinet is an extended linear site ( $\sim 50 \mathrm{~km}$ from north to south), and the disease entered the northern part of the study area several years before it spread to the south. The increase in prevalence at Freycinet therefore includes a component of spatial spread through the study site, in addition to increasing prevalence in individuals present at any given location. In contrast, the Fentonbury study site is smaller ( $\sim 5 \mathrm{~km}$ across in any direction), and the increase in the number of individuals infected at that site does not contain a substantial element of spatial spread.

The quantity that can be empirically measured from our data is $r_{0}$, which is the increase in prevalence per unit of time, on a logarithmic scale. However, the parameter of key epidemiological interest for management purposes is $R_{0}$, the basic reproductive rate, which is measured on a per generation scale. Unfortunately, a complicating factor in this case is that we do not have a good measure of the generation time of the disease, which is the mean time between an individual acquiring infection and transmitting it to another (Svensson 2007). For a given value of $r_{0}, R_{0}$ is greater for a longer generation time. The lack of knowledge of the generation time is responsible for the very large differences in the plausible values for $R_{0}$ shown in Table 7 . If the lower estimates are closer to the true value, then controlling the disease by vaccination or by the removal of infected animals may well be feasible. For example, developing a vaccine is a potential management strategy (Woods et al. 2007). A standard equation (Anderson and May 1991) for the proportion of individuals $p$ that must be vaccinated in order to eliminate a disease from a population is

$$
p=1-1 / R_{0} .
$$

TABLE 7. (A) Estimates of $r_{0}$ (the initial increase in prevalence per year), derived from generalized mixed models of prevalence in 2-3-year-olds vs. time in years, and (B) estimates of $R_{0}$ (the basic reproduction number), derived from Eq. 1 for plausible values of the generation time of the disease $(T$, in years).

\begin{tabular}{lccccccr}
\hline \hline & \multicolumn{3}{c}{ Freycinet } & & \multicolumn{3}{c}{ Fentonbury } \\
\cline { 2 - 3 } Statistic & $2.5 \%$ & Estimate & $97.5 \%$ & & $2.5 \%$ & Estimate & $97.5 \%$ \\
\hline A) $r_{0}$ & 0.6257 & 1.0055 & 1.2912 & & 1.4663 & 2.2644 & 3.1208 \\
B) $R_{0}$ & & & & & & \\
$T=0.25$ & 1.169 & 1.286 & 1.381 & & 1.443 & 1.761 & 2.182 \\
$T=0.50$ & 1.367 & 1.653 & 1.907 & & 2.082 & 3.102 & 4.761 \\
$T=0.75$ & 1.599 & 2.126 & 2.634 & & 3.003 & 5.465 & 10.387 \\
$T=1.00$ & 1.870 & 2.733 & 3.637 & & 4.333 & 9.625 & 22.664 \\
\hline
\end{tabular}

Note: The percentiles shown $(2.5 \%, 97.5 \%)$ were derived from Highest Posterior Density intervals for $r_{0}$ from a Markov chain Monte Carlo sample ( $n=50000$ iterations). 

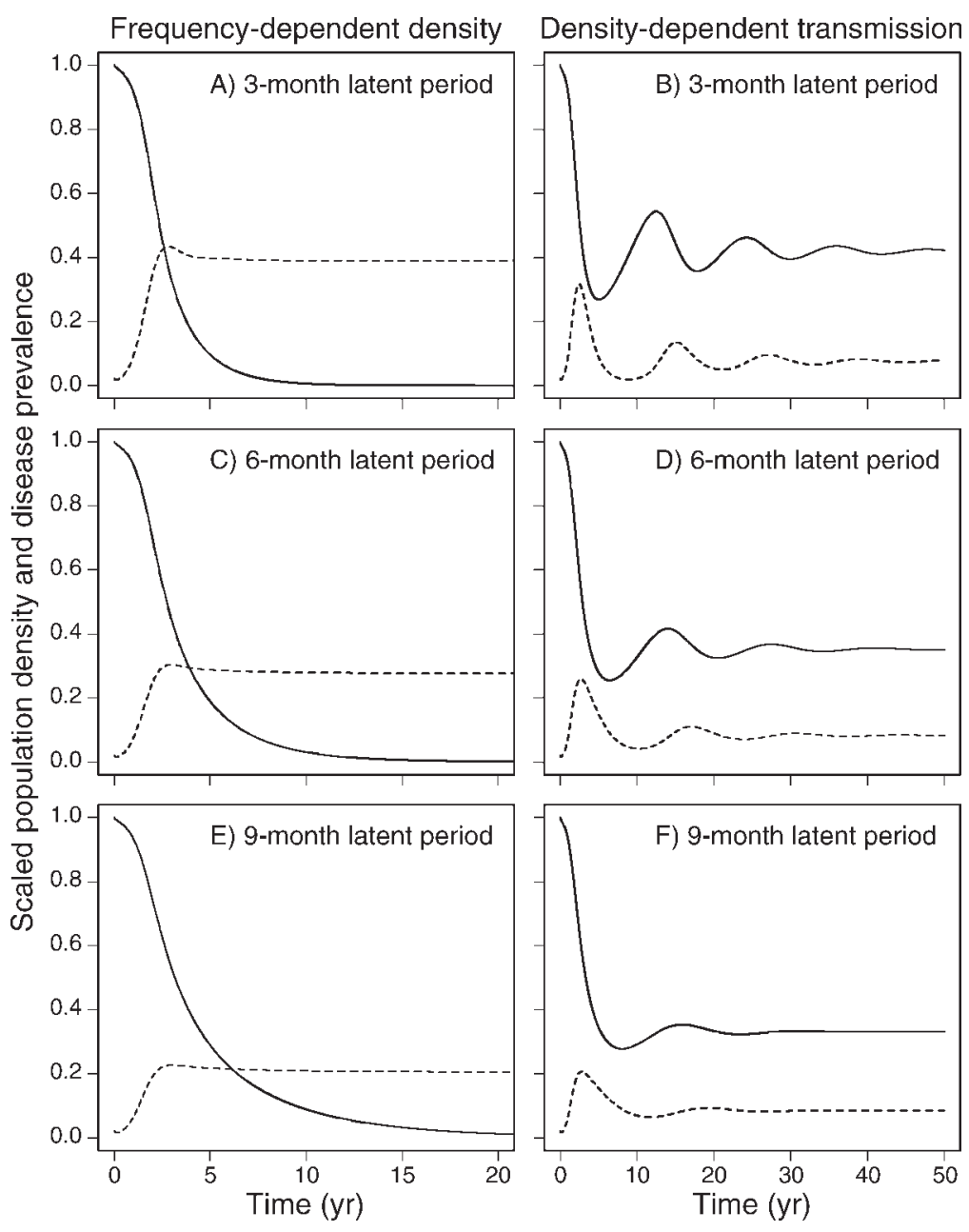

FIG. 6. Solutions of a simple age-structured model of Tasmanian devil-DFTD dynamics, with frequency-dependent disease transmission (A, C, and E) and density-dependent disease transmission (B, D, and F). In each, Tasmanian devil population density through time, scaled relative to the disease-free equilibrium population (solid line) and disease prevalence in animals two years and older (dashed line) are shown. Transmission for both density-dependent and frequency-dependent models was scaled so that the initial increase in prevalence matched that at Fentonbury $\left(2.26 \mathrm{yr}^{-1}\right)$ and the maximum rate of increase of the devil population, $r_{\max }$, was set at $0.3 \mathrm{yr}^{-1}$. As the latent period is the most poorly known parameter, results for latent periods of (A, B) 3 months, (C, D) 6 months, and (E, F) 9 months are shown. The mortality rates of susceptible and exposed devils are: $0.211,0.144,0.133,0.146$,

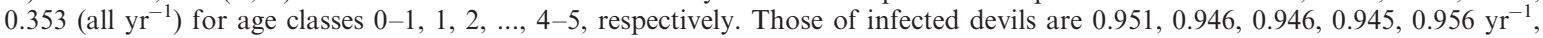
which represents an additional age-independent mortality rate of $93.8 \%$ per year.

Given the mean estimated value for $R_{0}$ at Freycinet and a generation time of six months, this would suggest that vaccination of only $\sim 30 \%$ of the population would be sufficient to eliminate the disease. Tasmanian devils are relatively trappable: mark-recapture models from Freycinet estimate the capture probability over a seven-day field trip of an individual known to be present in the population at $79 \%$ (Lachish et al. 2007). Even allowing for the possibility that some proportion of the population might be untrappable, this high recapture probability suggests that vaccination of $30 \%$ of the population might be achievable even if a vaccine needed to be delivered by injection. However, if the estimated value of $r_{0}$ at Fentonbury is closer to the typical value and the generation time is one year, then in excess of $80 \%$ of the population would need to be vaccinated, which would be more difficult to achieve.

The possibility of controlling the disease by selective culling of symptomatic infected animals is under active experimental investigation (Jones et al. 2007). Whereas vaccination aims to limit transmission by reducing the susceptible host population, selective culling aims to limit transmission by reducing the infected host population. The proportion of infected hosts that must be removed per unit of time to eliminate disease would not have a simple form like Eq. 6, because culling, unlike vaccination, will change overall host density. Nevertheless, this proportion will be a function of $R_{0}$, as disease elimination by whatever means requires driving $R_{0}$ to below 1 . 
Clearly, a priority for future research must be to produce estimates of the incubation period for the disease to enable more accurate estimation of $R_{0}$. However, this is not a straightforward exercise. Even in human disease epidemics when the onset of each individual case is known, estimating the serial interval is a substantial statistical challenge (White and Pagano 2008). Limited evidence from a very small number of laboratory transmission trials (Pyecroft et al. 2007) suggests that the incubation period may depend strongly on the mode of transmission. Experimentally duplicating contacts that are typical for devils interacting in the field is not easy, although confining an infected devil together with susceptible individuals for a short period of time might be possible. Another approach would be to bring animals without disease signs from a diseased area into captivity and then to monitor the time taken until clinical disease was observable. The longest periods measured would produce an estimate of the incubation period that was biased low, but would be an improvement on the anecdotal information currently available. A further possibility might be to measure tumor growth through time in a number of individuals and then attempt to extrapolate backwards to estimate the time of first infection. This would assume that tumor growth was monophasic.

Tasmanian devil facial tumor disease is, to our knowledge, the first case of a host-specific disease threatening to cause the extinction of its host. Detecting the nature of the relationship between transmission and host density is difficult in free-ranging populations (Begon et al. 2003, Rachowicz and Briggs 2007, Davis et al. 2008). The extensive field data analyzed in this study strongly suggest that DFTD transmission cannot be adequately represented by a simple density-dependent model, and therefore that extinction of the Tasmanian devil from this host-specific pathogen is a real possibility. This worrying prognosis for devil populations in the absence of intervention is central to determining appropriate management strategies and indicates the need for substantial investment in establishing diseasefree insurance populations, so that disease-free animals can be reintroduced following disease-induced extinction (Jones et al. 2007).

This case study emphasizes the importance of rapidly implementing monitoring programs, should an emerging pathogen be detected in any wildlife species. It is principally from the sites monitored since the first arrival of the disease that we have been able to estimate parameters associated with disease transmission. This information has been critical in determining the prognosis for the species and in justifying the very substantial investment that has been made by Australian governments in its conservation.

\section{ACKNOWLEDGMENTS}

Funding support for this project was provided by the Australian Research Council (Linkage Grant LP0561120 to M. E. Jones and H. McCallum and Discovery Grants
DP0451402 and DP0772644 to H. McCallum) and by the Tasmanian and Australian Governments through the "Save the Tasmanian Devil" program. We are grateful to Nick Mooney, Jason Wiersma, Fiona Hume, Dydee Mann, Chris Spencer, and a large number of volunteers who have assisted with the fieldwork over many years. We also thank the Parks and Wildlife Service, Forestry Tasmania, Gunns Limited, and a number of private landowners for permission to carry out research on their land. All fieldwork was carried out under Animal Ethics permits from the Tasmanian Department of Primary Industries and Water and/or the University of Tasmania.

\section{Literature Cited}

Anderson, R. M. 1991. Discussion: the Kermack-McKendrick epidemic threshold theorem. Bulletin of Mathematical Biology 53:3-32.

Anderson, R. M., C. Fraser, A. C. Ghani, C. A. Donnelly, S. Riley, N. M. Ferguson, G. M. Leung, T. H. Lam, and A. J. Hedley. 2004. Epidemiology, transmission dynamics and control of SARS: the 2002-2003 epidemic. Philosophical Transactions of the Royal Society B 359:1091-1105.

Anderson, R. M., and R. M. May. 1991. Infectious diseases of humans. Oxford University Press, Oxford, UK.

Begon, M., S. M. Hazel, S. Telfer, K. Bown, D. Carslake, R. Cavanagh, J. Chantrey, T. Jones, and M. Bennett. 2003. Rodents, cowpox virus and islands: densities, numbers and thresholds. Journal of Animal Ecology 72:343-355.

Berger, L., et al. 1998. Chytridiomycosis causes amphibian mortality associated with population declines in the rain forests of Australia and Central America. Proceedings of the National Academy of Science (USA) 95:9031-9036.

Burnham, K. P., and D. R. Anderson. 2004. Multimodel inference: understanding AIC and BIC in model selection. Sociological Methods Research 33:261-304.

Chao, A., S. M. Lee, and S. L. Jeng. 1992. Estimating population size for capture-recapture data when capture probabilities vary by time and individual animal. Biometrics 48:201-216.

Cockburn, A., and C. N. Johnson. 1988. Patterns of growth. Pages $28-40$ in C. H. Tyndale-Biscoe and P. A. Janssens, editors. The developing marsupial models for biomedical research. Springer Verlag, Berlin, Germany.

Cooch, E., and G. White. 2002. Using MARK - a gentle introduction. Second edition. 〈http://www.biol.sfu.ca/cmr/ mark $/\rangle$

Davis, S., P. Trapman, H. Leirs, M. Begon, and J. A. P. Heesterbeek. 2008. The abundance threshold for plague as a critical percolation phenomenon. Nature 454:634-637.

de Castro, F., and B. Bolker. 2005. Mechanisms of diseaseinduced extinction. Ecology Letters 8:117-126.

Ferguson, N. M., C. A. Donnelly, and R. M. Anderson. 2001. Transmission intensity and impact of control policies on the foot and mouth epidemic in Great Britain. Nature 413: 542-548.

Fowler, C. W. 1981. Density dependence as related to life history strategy. Ecology 62:602-610.

Grenfell, B. T., and R. M. Anderson. 1985. The estimation of age-related rates of infection from case notifications and serological data. Journal of Hygiene 95:419-436.

Hamede, R., M. E. Jones, and H. McCallum. 2008. Seasonal, demographic and density-related patterns of contact between Tasmanian devils (Sarcophilus harrisii): implications for transmission of Devil Facial Tumour Disease. Austral Ecology 33:614-622.

Hawkins, C. E., C. Baars, H. Hesterman, G. J. Hocking, M. E. Jones, B. Lazenby, D. Mann, N. Mooney, D. Pemberton, S. Pyecroft, M. Restani, and J. Wiersma. 2006. Emerging disease and population decline of an island endemic, the Tasmanian devil Sarcophilus harrisii. Biological Conservation 131:307-324. 
Hesterman, H. 2008. Reproductive biology and behaviour of the Tasmanian devil and spotted-tailed quoll. Dissertation. University of Tasmania, Hobart, Tasmania.

Hoffmann, M., C. E. Hawkins, and P. D. Walsh. 2008. Action needed to prevent extinctions caused by disease. Nature 454 : $159-159$.

Jones, M. E., A. Cockburn, R. Hamede, C. Hawkins, H. Hesterman, S. Lachish, D. Mann, H. McCallum, and D. Pemberton. 2008. Life history change in disease-ravaged Tasmanian devil populations. Proceedings of the National Academy of Science (USA) 105:10023-10027.

Jones, M., P. Jarman, C. Lees, H. Hesterman, R. Hamede, N. Mooney, D. Mann, C. Pukk, J. Bergfeld, and H. McCallum. 2007. Conservation management of Tasmanian devils in the context of an emerging, extinction-threatening disease: Devil Facial Tumor Disease. EcoHealth 4:326-337.

Kenward, R. E. 1985. Ranging behaviour and population dynamics in grey squirrels. Pages $319-330$ in R. M. Sibly and R. H. Smith, editors. Behavioural ecology: ecological consequences of adaptive behaviour. Blackwell Scientific, Oxford, UK.

Lachish, S., M. E. Jones, and H. I. McCallum. 2007. The impact of devil facial tumour disease on the survival and population growth rate of the Tasmanian devil. Journal of Animal Ecology 76:926-936.

Lachish, S., H. McCallum, and M. Jones. 2009. Demography, disease and the devil: life-history changes in a disease-affected population of Tasmanian devils Sarcophilus harrisii. Journal of Animal Ecology 78:427-436.

Lafferty, K. D., and L. R. Gerber. 2002. Good medicine for conservation biology: the intersection of epidemiology and conservation theory. Conservation Biology 16:593-604.

Leroy, E. M., P. Rouquet, P. Formenty, S. Souquiere, A. Kilbourne, J.-M. Froment, M. Bermejo, S. Smit, W. Karesh, R. Swanepoel, S. R. Zaki, and P. E. Rollin. 2004. Multiple Ebola virus transmission events and rapid decline of Central African wildlife. Science 303:387-390.

Lips, K. R., F. Brem, R. Brenes, J. D. Reeve, R. A. Alford, J. Voyles, C. Carey, L. Livo, A. P. Pessier, and J. P. Collins. 2006. Emerging infectious disease and the loss of biodiversity in a Neotropical amphibian community. Proceedings of the National Academy of Science (USA) 103:3165-3170.

Lipsitch, M., T. Cohen, B. Cooper, J. M. Robins, S. Ma, L. James, G. Gopalakrishna, S. K. Chew, C. C. Tan, M. H Samore, D. Fisman, and M. Murray. 2003. Transmission dynamics and control of severe acute respiratory syndrome. Science 300:1966-1970.

Lloyd-Smith, J. O., P. C. Cross, C. J. Briggs, M. Daugherty, W. M. Getz, J. Latto, M. S. Sanchez, A. B. Smith, and A. Swei. 2005. Should we expect population thresholds for wildlife disease? Trends in Ecology and Evolution 20:511-519.

Loh, R., J. Bergfeld, D. Hayes, A. O'Hara, S. Pyecroft, S. Raidal, and R. Sharpe. 2006. The pathology of Devil Facial Tumor Disease (DFTD) in Tasmanian devils (Sarcophilus harrisii). Veterinary Pathology 43:890-895.

McCallum, H. 2008. Tasmanian devil facial tumour disease: lessons for conservation biology. Trends in Ecology and Evolution 23:631-637.

McCallum, H. I., and A. P. Dobson. 1995. Detecting disease and parasite threats to endangered species and ecosystems. Trends in Ecology and Evolution 10:190-194.

McCallum, H., D. M. Tompkins, M. Jones, S. Lachish, S. Marvanek, B. Lazenby, G. Hocking, J. Wiersma, and C. Hawkins. 2007. Distribution and impacts of Tasmanian devil facial tumor disease. EcoHealth 4:318-325.

Otis, D. L., K. P. Burnham, G. C. White, and D. R. Anderson. 1978. Statistical inference from capture data on closed animal populations. Wildlife Monographs 62:7-135.
Pearse, A.-M., and K. Swift. 2006. Allograft theory: transmission of devil facial-tumour disease. Nature 439:549.

Pemberton, D. 1990. Social organisation and behaviour of the Tasmanian devil Sarcophilus harrisii. Dissertation. University of Tasmania, Hobart, Tasmania, Australia.

Pyecroft, S. B., A.-M. Pearse, R. Loh, K. Swift, K. Belov, N. Fox, E. Noonan, D. Hayes, A. D. Hyatt, L. F. Wang, D. B. Boyle, J. S. Church, D. J. Middleton, and R. J. Moore. 2007. Towards a case definition for Devil Facial Tumour Disease: What is it? EcoHealth 4:346-351.

R Development Core Team. 2007. R: a language and environment for statistical computing. R Foundation for Statistical Computing, Vienna, Austria.

Rachowicz, L. J., and C. J. Briggs. 2007. Quantifying the disease transmission function: effects of density on Batrachochytrium dendrobatidis transmission in the mountain yellow-legged frog Rana muscosa. Journal of Animal Ecology 76:711-721.

Randall, D. A., J. Marino, D. T. Haydon, C. Sillero-Zubiri, D. L. Knobel, L. A. Tallents, D. W. Macdonald, and M. K. Laurenson. 2006. An integrated disease management strategy for the control of rabies in Ethiopian wolves. Biological Conservation 131:151-162.

Real, L. A., and R. Biek. 2007. Infectious disease modeling and the dynamics of transmission. Pages 33-49 in J. E. Childs, J. S. MacKenzie, and J. A. Richt, editors. Wildlife and emerging zoonotic diseases: the biology, circumstances and consequences of cross-species transmission. Springer, Berlin, Germany.

Rexstad, E., and K. Burnham. 1992. User's guide for interactive program CAPTURE. Colorado Cooperative Fish and Wildlife Research Unit, Colorado State University, Fort Collins, Colorado, USA.

Roberts, M. G. 2007. The pluses and minuses of R-0. Journal of the Royal Society Interface 4:949-961.

Roberts, M. G., and J. A. P. Heesterbeek. 2007. Modelconsistent estimation of the basic reproduction number from the incidence of an emerging infection. Journal of Mathematical Biology 55:803-816.

Siddle, H. V., A. Kreiss, M. D. B. Eldridge, E. Noonan, C. J. Clarke, S. Pyecroft, G. M. Woods, and K. Belov. 2007. Transmission of a fatal clonal tumor by biting occurs due to depleted MHC diversity in a threatened carnivorous marsupial. Proceedings of the National Academy of Sciences (USA) 104:16221-16226.

Svensson, A. 2007. A note on generation times in epidemic models. Mathematical Biosciences 208:300-311.

van Riper, C., S. G. van Riper, M. Lee Goff, and M. Laird. 1986. The epizootiology and ecological significance of malaria in Hawaiian land birds. Ecological Monographs 56:327-344.

van Riper, C., S. G. van Riper, and W. R. Hansen. 2002. Epizootiology and effect of avian pox on Hawaiian forest birds. Auk 119:929-942.

Vial, F., S. Cleaveland, G. Rasmussen, and D. T. Haydon. 2006. Development of vaccination strategies for the management of rabies in African wild dogs. Biological Conservation 131:180-192.

White, L. F., and M. Pagano. 2008. A likelihood-based method for real-time estimation of the serial interval and reproductive number of an epidemic. Statistics in Medicine 27:2999 3016.

Woods, G. M., A. Kreiss, K. Belov, H. V. Siddle, D. L. Obendorf, and H. K. Muller. 2007. The immune response of the Tasmanian Devil (Sarcophilus harrisii) and Devil Facial Tumour Disease. EcoHealth 4:338-345. 